\title{
O cuidado em saúde na velhice: a visão do homem'
}

\section{The healthcare in aging: the men's view}

Juliana Sousa Coelho

Centro de Pesquisas René Rachou/FIOCRUZ, Programa de Pós- graduação em Saúde Coletiva. Belo Horizonte, MG, Brasil.

E-mail: juliana.coelhoळcpqrr.fiocruz.br

Karla C. Giacomin

Fundação Oswaldo Cruz

Universidade Federal de Minas Gerais. Núcleo de Estudos em Saúde

Pública e Envelhecimento. Belo Horizonte, MG, Brasil.

E-mail: kcgiacominळhotmail.com

Josélia Oliveira Araújo Firmo

Fundação Oswaldo Cruz

Universidade Federal de Minas Gerais. Núcleo de Estudos em Saúde

Pública e Envelhecimento. Belo Horizonte, MG, Brasil.

E-mail: firmojळcpqrr.fiocruz.br

\section{Correspondência}

Josélia Oliveira Araújo Firmo

Av. Augusto de Lima, 1715, Belo Horizonte, MG, Brasil. CEP 30190-002

\section{Resumo}

A cultura condiciona as representações de velhice e de gênero com reflexos nas percepções sobre a saúde, a doença e o cuidado. A interface entre esses fenômenos é objeto deste estudo, fundamentado na perspectiva da antropologia médica, que pretende investigar como os homens idosos da comunidade expressam e percebem a relação entre saúde, doença, masculinidade e envelhecimento, e como esses construtos se relacionam com os subsistemas de cuidado informal e profissional.

Foram entrevistados 27 homens com 60 anos ou mais, residentes em Bambuí (MG) e assistidos pela Estratégia Saúde da Família, acerca de suas atividades cotidianas, sua saúde e suas formas de cuidado. 0 modelo de signos, significados e ações, utilizado na coleta e análise dos dados, permitiu reconhecer as maneiras típicas de pensar e agir de homens idosos em relação ao processo saúde-doença-cuidado, bem como suas interações e contradições junto aos setores profissional e informal do sistema de cuidado em saúde.

A produção material e simbólica dos entrevistados demonstra a identidade masculina ligada ao conceito de saúde, o qual se vincula às relações sociais, que fundamentam o cuidado informal à saúde. Contrapondo-se a essa percepção está a visão de envelhecimento inexoravelmente relacionada à doença, em que se ancora o sistema profissional de cuidado. Assim, homens idosos restringem a procura por cuidados em saúde em parte pela própria construção sociocultural da masculinidade que renega a fragilidade, mas também porque as ações e os profissionais de saúde desconsideram as especificidades de gênero e o valor dado pelos homens idosos à independência funcional.

Palavras-chave: Envelhecimento; masculinidade; cuidado em saúde. 


\section{Abstract}

Culture determines representations of old age and gender that influence the perceptions of health, illness and care. The interface between these phenomena is the object of this study, based on the perspective of medical anthropology, which aims to investigate how older men from community express and perceive the relationship between health, disease, aging and masculinity, and how these social constructs relate to subsystems informal and professional care.

We interviewed 27 men aged 60 or older, living in Bambuí (MG) and assisted by the Family Health Strategy, about their daily activities, their health and their forms of healthcare. The model of signs, meanings and actions, used in the collection and analysis of data, allowed recognizing the typical ways of thinking and acting of older men in relation to the health-illness-care process, as well as their interactions and contradictions regarding to the professional and informal sectors of healthcare system.

The material and symbolic production of the respondents shows that in general the male identity is linked to the concept of health, which is tied to the social relations that underlie the informal healthcare. Opposed to this perception is the aging view inexorably related to sickness, in which the professional care system is anchored. Thus, older men restrict their demand for healthcare in part because their own socio-cultural construction of masculinity denies the frailty, but also this is due to the health actions and health professionals that ignore the specificities of gender and the value of the functional independence to older men.

Keywords: Aging; Masculinity; Healthcare.

\section{Introdução}

Questões do gênero influenciam a conduta e os hábitos de vida masculinos, produzindo modos de cuidar, adoecer e envelhecer (Burille, 2012). Para Scott (1989), a definição de gênero envolve a noção da construção social das identidades subjetivas dos homens e das mulheres, que engloba, mas também ultrapassa, as diferenças sexuais biológicas, articulada à noção das relações de poder. Essa é uma abordagem complexa que articula as dimensões biológica e sociocultural. A primeira determina alguma distinção de saúde entre mulheres e homens, como a prevalência de doenças; a segunda refere-se às questões de natureza política, social e econômica que trazem disparidades na saúde entre os gêneros (Marques, 2010). Essas diferenças socialmente construídas determinam papéis sociossexuais que levam a diferentes padrões de cuidado e tipos de riscos para a saúde (Marques, 2010), condicionados pelas experiências e relações entre as pessoas em contextos específicos que perpassam as definições e as formas de agir relacionadas aos significados de homem e mulher em diferentes culturas. Entende-se como cultura um universo específico de símbolos e significados que permite a cada sociedade interpretar a vida e suas experiências e guiar suas formas de agir e se organizar (Geertz, 1989). Essa teia de significados condiciona as noções de gênero (O'Brien; Kunt; Hart, 2005), bem como as diferentes representações da velhice e a importância social dos velhos na comunidade e nas famílias (Uchôa; Firmo; Lima-Costa, 2002).

Schraiber, Gomes e Couto (2005) e O'Brien, Kunt e Hart (2005) observam uma crescente preocupação com a saúde do homem e o aumento de estudos diretamente relacionados ao assunto nas últimas décadas. Porém, a inclusão da perspectiva do homem no debate da saúde precisa transpor as questões relacionadas ao corpo masculino, como a saúde sexual, principalmente relacionada às doenças sexualmente transmissíveis, e a saúde reprodutiva. Afinal, os homens e suas necessidades de saúde são plurais, por isso é importante reconhecer como eles as expressam e como tais necessidades 
estão sendo absorvidas pelos sistemas de cuidado em saúde. Além disso, a perspectiva de gênero tem sido historicamente abordada a partir de bases feministas (Scott, 1989), limitando a discussão de planos de ação para o cuidado ao homem pouco além do estereótipo de que "o homem depende de uma figura feminina para se cuidar".

Culturalmente, a socialização dos homens não inclui a valorização do cuidado de si e dos outros (Schraiber; Gomes; Couto, 2005). Pelo contrário, usualmente, o homem é expulso, e a si mesmo expulsa do cenário do cuidado (Gutierrez; Minayo, 2008). Por sua vez, na compreensão do processo saúde-doença-cuidado, cada grupo ou indivíduo de uma determinada faixa etária, gênero, contexto sociocultural, constrói sua concepção sobre a saúde e a doença, associada às questões culturais e às vivências pessoais, e, a partir deste entendimento, são definidos os modelos de cuidado (Gutierrez; Minayo, 2008).

No presente estudo, entendemos cuidado como parte de um sistema cultural, construído a partir de um contexto social e de experiências pessoais, atravessados por fatores políticos, econômicos, históricos e biológicos (Kleinman, 1978). O cuidado em saúde envolve ações técnicas, políticas e éticas no acolhimento das pessoas na busca por atender suas necessidades. Essa compreensão ampla da dimensão do cuidado se opõe às práticas homogeneizantes e hierarquizantes da atenção biomédica predominante, pois considera as identidades, experiências, intersubjetividades e saberes dos envolvidos (Mandú, 2004).

0 momento atual de acelerada transição demográfica nos obriga a repensar os sistemas de cuidado, pois, mais do que um fenômeno biológico, envelhecer é um fato social, cuja elaboração simbólica encontra-se atrelada a um universo social e cultural específico (Giacomin; Uchôa; Lima-Costa, 2005; Uchôa; Firmo; Lima-Costa, 2002). É preciso refletir sobre como garantir qualidade de vida à sociedade, lançando mão de novas tecnologias da engenharia médica e rediscutindo as formas mais adequadas de cuidado, que ultrapassem as questões de consumo geriátrico de interesse do mercado e a extensa teia de proibições e regras que a noção matemática do risco impõe a essa fase da vida (Minayo; Coimbra Jr., 2002).

Além disso, à medida que cada vez mais pessoas idosas ocupam espaços de participação social, constituindo-se como fortes atores sociais e políticos e consolidam uma nova identidade coletiva de idosos (Minayo; Coimbra Jr., 2002), reforça-se a necessidade de mudança da cultura que obscurece os atributos da idade passando a compreender a velhice como um tempo específico e natural da vida. Assim, quando se trata de homens que vivenciam o próprio envelhecimento, o comportamento masculino no cuidado à saúde é interpelado por questões relacionadas à fragilidade, à incapacidade e, muitas vezes, à dependência e, consequentemente à necessidade de cuidado formal - pelo sistema de saúde - e informal - pela família.

Tomando como referência as proposições de Kleinman (1978) sobre os sistemas de cuidado à saúde, em uma abordagem interpretativa da antropologia médica, as estratégias de busca pelo cuidado em saúde são diversas e articulam a capacidade do próprio indivíduo e os recursos disponíveis no meio, portanto sua amplitude de ações se dá em várias dimensões: informal, popular e profissional (Helman, 2003; Kleinman, 1978). Além disso, é notória a relevância do setor informal, que inclui o autotratamento e medicalização, assim como a obtenção de conselhos com amigos ou parentes, respondendo pela resolução de 70 a 90\% dos problemas de saúde (Kleinman, 1978). Apesar da importância desses três setores em integração, para Amadigi et al. (2009) em relação ao sistema profissional do cuidado, há uma dificuldade motivada pela formação biomédica dos trabalhadores da saúde, que não contempla a subjetividade humana e a determinação da cultura, o que explica os profissionais não reconhecerem o saber e as práticas de cuidado dos usuários, mantendo com estes uma relação de poder assimétrica.

O objetivo deste estudo foi investigar as concepções de saúde-doença, masculinidade e envelhecimento de homens idosos da comunidade e sua interação com os subsistemas de cuidado informal e profissional. 


\section{Percurso metodológico}

Este trabalho de cunho antropológico é parte do projeto "Abordagem da dinâmica de funcionalidade em idosos", que investiga a funcionalidade como um componente essencial da saúde da pessoa idosa. A pesquisa foi conduzida na área urbana da cidade de Bambuí, centro-oeste do estado de Minas Gerais, com 22.734 habitantes (IBGE, 2010), município que, seguindo a tendência brasileira, passa por um progressivo fenômeno de urbanização e envelhecimento. Sua população rural, que representava $84 \%$ em 1950, passou para $15 \%$ da população total do município em 2010; enquanto no mesmo período, os habitantes com 60 ou mais anos de idade passaram de menos de $4 \%$, para quase $16 \%$ em 2010 , sendo $45 \%$ homens. A economia da cidade de Bambuí tem a sua principal fonte de renda proveniente da exploração produtiva de seus recursos naturais, em atividades agrícolas, pecuária e de extração mineral. Porém o Mapa da Pobreza e Desigualdade do município mostra que há uma incidência de 32,47\% da população em estado de pobreza (IBGE, 2010). A taxa de analfabetismo da população de 15 anos ou mais de idade em 2000 representava $11,9 \%$ e em 2010 passou para $7,6 \%$, porém entre os idosos esse índice mantém-se alto, em 22,1\%. A maioria dos idosos segue a religião católica e são oriundos da área rural.

A rede pública de assistência à saúde contava com seis Unidades Básicas de Saúde (UBS) que integram a Estratégia de Saúde da Família (ESF), uma policlínica, uma unidade do Núcleo de Apoio à Saúde da Família (NASF), dois hospitais - um estadual e um municipal (BRASIL, 2010) e o Posto Avançado de Estudos Emanuel Dias (FIOCRUZ), que se destaca no controle da Doença de Chagas. Em 2010 a cobertura da ESF era de $92 \%$ e estavam cadastradas 3.694 pessoas maiores de 60 anos, sendo 1.652 homens idosos (BRASIL, 2010).

$\mathrm{O}$ universo pesquisado incluiu idosos (idade 60 anos), de ambos os sexos, variados níveis funcionais, residentes em diferentes regiões da cidade, desde que cadastrados e assistidos pela ESF, e sem alterações cognitivas que impedissem a realização das entrevistas. 0 critério de saturação regulou o tamanho da amostra (Turato, 2005). Para o presente estudo somente foram selecionados os participantes do sexo masculino.

O modelo de "Signos, Significados e Ações" (Corin et al., 1992) foi utilizado na coleta e análise dos dados, para permitir a sistematização dos elementos do contexto que participam da construção de maneiras típicas de pensar e agir de homens idosos em relação ao processo saúde-doença-cuidado e envelhecimento. Parte-se de uma perspectiva êmica, isto é, construída na perspectiva dos entrevistados e não como uma discussão na visão do pesquisador ou da literatura (Turato, 2005). As entrevistas foram realizadas no domicílio de cada entrevistado, a partir de roteiros semiestruturados, o que permite a ampliação do campo de fala dos idosos e um mergulho no ambiente local e cultural do sujeito, onde ele se organiza e confere significados particulares a sua experiência. Todas as entrevistas foram gravadas, após consentimento livre e esclarecido dos informantes, transcritas, informatizadas e submetidas a uma análise criteriosa. Assim, as vozes dos homens idosos relatando sobre a vida, sua saúde e suas formas de cuidado foram o ponto de partida para reconstruir o universo de representações (maneiras de pensar) e comportamentos (maneiras de agir) para identificar o(s) significado(s) que os homens idosos conferem ao processo saúde-doença-cuidado.

O projeto foi aprovado no Comitê de Ética em pesquisa com seres humanos do Centro de Pesquisa René Rachou/FIOCRUZ (CAAE: oo28.0.245.00oo9). Todos os participantes assinaram termo de consentimento (Resolução nº196/1996 do Conselho Nacional de Saúde).

\section{Resultados e Discussão}

Foram entrevistados 27 homens com idades entre 61 e 96 anos, sendo 10 sexagenários; nove septuagenários; seis octogenários e dois nonagenários. Dezessete entrevistados eram casados e um vivia em união estável, seis eram viúvos e três, solteiros. Vinte e três tiveram filhos. Somente cinco relataram morar sozinhos. Entre os entrevistados observa-se forte influência da religião católica e prevalece um baixo grau de escolaridade: apenas três informaram possuir curso superior. 
O significado que esses homens idosos dão ao envelhecimento é demonstrado pela produção material e simbólica, que inclui a elaboração sobre a identidade masculina e os reflexos dessas percepções em suas concepções de saúde, de doença e dos tipos de cuidado que recebem nesse período de suas vidas. Emergiram das entrevistas, três categorias de análise relacionadas à forma como os entrevistados expressam suas percepções sobre o processo saúde-doença-cuidado: o ethos masculino como sinônimo de saúde; a relação entre velhice e doença; as contradições do cuidado.

\section{O ethos masculino como sinônimo de saúde}

Nesta categoria, emergem as características que constroem o ethos masculino no universo pesquisado. Nesse universo, todos os entrevistados são idosos, vivem em um município do interior e valorizam sua origem rural e sua ligação afetiva com o campo, onde praticavam atividades desgastantes ligadas ao uso da força física, e socialmente vinculadas aos homens e seus atributos de masculinidade (Nardi, 1998), como o trabalho na roça de sol a sol ou em carvoaria.

Segundo o dicionário Houaiss (2001, p. 1271) ethos é uma expressão de origem grega que significa "conjunto dos costumes e hábitos fundamentais, no âmbito do comportamento (instituições, afazeres etc.) e da cultura (valores, ideias ou crenças), característicos de uma determinada coletividade, época ou região; na antropologia norte-americana, reunião de traços psicossociais que definem a identidade de uma determinada cultura; personalidade de base". Assim, os ethos masculinos são identidades masculinas construídas a partir das maneiras de ser de cada grupo (Nardi, 1998). Connel (2005) apresenta as múltiplas masculinidades cujos padrões podem variar considerando a época, a região, a classe, a geração, além das relações interpessoais e valores morais de cada grupo. Isso nos leva ao entendimento que as definições culturais de masculinidade são construções históricas e dinâmicas através das quais os indivíduos interpretam as experiências e geram comportamentos.
Segundo os entrevistados, ainda que preferissem o campo, a insuficiência de recursos econômicos e sociais na zona rural serviu como motivação para a mudança para a cidade, seja "por conta de estudar os meninos"(H40, 71 anos, casado), seja para facilitar a vida pós-envelhecimento, como explica este homem: "meus filhos achou que eu tava sofrendo sozinho na roça" (H26, 85 anos, viúvo). Outro homem explica por que é bom morar em Bambuí:

Aqui a gente tem muita facilidade, para as coisas. Porque eu acho difícil lá em Belo Horizonte. [...] $\dot{\varepsilon}$ onde que eu gosto daqui, aqui eu quero ir lá embaixo eu vou lá, os negócio que eu preciso, qualquer banda de a pé, não tem nada custoso aqui. Por isso que a gente acha que aqui é mais fácil (H3, 74 anos, casado).

As características apontadas (tranquilidade, acessibilidade e proximidade entre os serviços e os negócios de seu interesse) são muito benéficas para essa fase da vida, pois prolongam a autonomia dos idosos. Segundo Ribeiro (2010), a independência possui significados associados a um modelo de envelhecimento bem-sucedido e ao ideal hegemônico de masculinidade, o qual tem no comportamento masculino de autossuficiência um de seus determinantes.

Embora conscientes de que o trabalho muitas vezes tenha sido causador de alguns dos problemas de saúde atuais, para os entrevistados estar trabalhando significa estar saudável, ser ativo. Dos relatos, emergem as diferenças percebidas entre os cotidianos do presente e do passado, com registros de saudosismo do trabalho e das atividades de outrora, como explica este senhor:

[...] eu trabalhei muito em serviço braçal, serviço pesado mesmo. Pra mim aquilo era uma beleza! Achava bom de mais! Ficar cansado de trabalhar bastante! Depois chegava, tomava banho, jantava, dava sono pra dormir. Era uma coisa boa (H12, 70 anos, solteiro).

Este entrevistado fala sobre o que a falta da atividade laboral representa para si: 
[...] nóis veio pra cá eu ficava na janela do quarto ali, ó. Não tinha condição de ir pro serviço, não aguentava sem chorar não. A recordação do serviço, do tempo que eu pegava, trabalhava (Ho7, 84 anos, casado).

Ainda que o trabalho colabore para o adoecimento ou dificulte o cuidado com a saúde, a falta do trabalho é aspecto importante relacionado aos riscos à saúde mental dos homens (Schraiber; Gomes; Couto, 2005), pois ele tem função estruturante na sociedade, sendo um elemento muito importante na constituição do ethos masculino, estabelecendo uma estreita relação entre ser homem e ser trabalhador (Nardi, 1998; Schraiber; Gomes; Couto, 2005). Esses aspectos apontam a posição paradoxal do trabalho, apresentada também por Schraiber, Gomes e Couto (2005), que, se por um lado ele representa a saúde, por outro lado o trabalho funciona como obstáculo, especialmente quando se trata do cuidado com a saúde. Por isso, o único entrevistado que continua trabalhando também reclama:

Agora a forma melhor que eu tô esperando, tô maneirando o meu campo pra mim aproveitar o que eu tenho no meu canto é essa aposentadoria pra salvar o meu... um cado da moda da minha diária, pra mim ter tempo pra mim dedicarno que eu quero fazer (H29, 65 anos, casado).

Para Ribeiro (2010), cada homem idoso traz uma forma de adequar sua realidade aos ideais de masculinidade, produtividade e de saúde, seguindo uma exigência do amadurecimento e das mudanças de papéis e relações sociais que levam à reconstrução e flexibilização desses conceitos, como uma forma de resiliência. No grupo pesquisado, a saída do mundo do trabalho provoca um transtorno, que para muitos simboliza uma morte social com reflexos na saúde, acarretando por vezes um mal maior que a realização do trabalho causava ao corpo, enquanto outros buscam se conformar à ociosidade. Um idoso esclarece como a velhice e a falta de trabalho afetam sua vida:

Ah ela [a velhice] tirou de mim o trabalho que toda vida eu gostei de fazer... A gente não tem mais aquela disposição pro trabalho que a gente tinha, não tem força... então essas coisas vão minando a gente devagarinho (H15, 79 anos, casado).

Segundo Nardi (1998), a ideologia produtivista hegemônica, pós Revolução Industrial, levou ao ápice a relação em que ser capaz de trabalhar é sinônimo de ser saudável, gerando a desvalorização daqueles que não estão aptos ao trabalho. Ao descartar as pessoas que não são capazes de trabalhar, essa ideologia reforça a discriminação contra o envelhecimento, reconhecendo essa fase da vida como um problema (Minayo; Coimbra Jr., 2002).

Na divisão sexual e social do trabalho, o espaço masculino é o espaço público do trabalho, onde ocorrem com mais intensidade suas relações sociais, mas a velhice e a aposentadoria retiram o homem desse espaço público, provocando uma ruptura de identificação. O homem, quando se aposenta, passa a ocupar um lugar indefinido, ao deixar de cumprir a norma internalizada de ser homem e ser trabalhador (Nardi, 1998). Essa situação exige uma ressignificação com a relativização desses papéis em uma estrutura menos rígida.

Quanto às atividades relacionadas ao lar, em geral a maioria dos entrevistados assume as tarefas ligadas ao entorno da moradia, como quintais, hortas ou pequenas criações de animais. Os cuidados domésticos são realizados predominantemente pelas mulheres presentes nas redes sociais dos entrevistados. Um entrevistado explica:

A gente fica desanimado! A gente, homem mexer em cozinha, quer dizer, faz a gente só, tudo bem, mas é o trem mais esquisito. Ah minha nossa Senhora! Até fazer comida, se puder, é lavar os trem. É ajeitar tudo e fazer o café, um trem assim, é custoso né? (H2O, 69 anos, solteiro).

Se o espaço do masculino é o público e suas características se relacionam com o conceito de saudável, o espaço privado é o do doente e da doença, que se conforma como fraqueza e incapacidade. É um espaço de domínio do feminino, tradicionalmente encarregado dos cuidados com o lar, a saúde e a doença (Nardi, 1998). Outro entrevistado manifesta 
seu desconforto face à perspectiva de experimentar alguma incapacidade e precisar de cuidados:

É... porque ajuda que a gente precisa é só se a gente tiver doente, fazer uma coisa pra gente que a gente não possa fazer. Assim, se eu tiver mais ou menos assim que nem eu to hoje, uma comparação, a maior parte que eu tô é assim mesmo... Eu tenho medo demais é de derrame... Ficar numa cadeira de rodas. Aí a gente sabe que a gente tem muita pessoa que faz as coisas pra gente, eu não tô achando ruim não, mas aqui em casa todo mundo tem uma vida (H12, 70 anos, solteiro).

Um homem explica como faz:

Não, tem coisa que é só a gente mesmo que dá conta de fazer.

[quando não dá conta, abandona e pronto]. $\varepsilon$ pronto! Esquece! (risos) (Hзо, 76 anos, solteiro).

No grupo, "dar conta" significa ser independente para realizar aquela atividade, enquanto, "não dar conta" exprime a incapacidade para fazê-lo, porém essa atividade pode ser abandonada - como no relato anterior - ou realizada de forma diferente. Todos os entrevistados declaram o medo da incapacidade, porém o medo de "dar trabalho", isto é, de depender do cuidado de alguém, é ainda maior, como pode ser notado neste excerto:

Eu não tenho medo da morte não, se falar assim: vai morrer amanhã, não tem problema. Eu tenho medo é de, por exemplo, eu sou assim, um pouco agitado, se eu cair numa cama e não puder andar, um trem assim, aí eu tenho medo, de ficar dando trabalho pros outros, ficar pela mão dos outros. Aí é preferivel que a gente morresse (risos) ( $\mathrm{H}_{18}$, 65 anos, casado).

Ribeiro (2010) relata a centralidade da identidade masculina na definição de saúde e de doença, sendo que a partir dessas definições e da perspectiva de gênero são negociadas as condições de vulnerabilidade física. Embora a perspectiva de envelhecer com limitações possa afetar indivíduos de ambos os sexos (Pereira; Firmo; Giacomin; 2014), considerando a construção de seu papel social como homem, para boa parte dos entrevistados, excluem-se os cuidados domésticos e às vezes até o cuidado de si. Esse território do espaço interno fica exclusivo para a figura feminina. Este homem reconhece:

...mas eu sei que vou morrer primeiro que minha esposa, isso não tem perigo, meu medo maior é não ter uma filha... mas graças a Deus tá aparecendo nora pra mim, quero que seja minha nora, quero que seja minha filha ( $\mathrm{H}_{57}, 62$ anos, casado).

Assim, depender de mulheres para a realização dos afazeres domésticos muitas vezes não se apresenta para esses idosos como incapacidade, nem se insere no receio de "dar trabalho", pois se ancora na relação de poder entre gêneros, que naturaliza o cuidado e as tarefas do lar como inatas à mulher, expressando o ethos na dominação masculina da divisão social do trabalho (Silva; Budó; Silva, 2013).

Connel (2005) cita a dificuldade masculina em lidar com problemas de saúde, inclusive a incapacidade. Os ethos masculinos presentes no discurso cotidiano hegemônico definem formas bem-sucedidas de "ser homem", que estão ligadas a força, autoridade, autossuficiência, independência, poder (Ribeiro, 2010). Tais elementos somente se associam ao estar saudável. Dessa forma, mitigar sintomas e problemas de saúde pode ser considerado um esforço para manter essa identidade masculina, ou ainda a questão de como o idoso entende o conceito de saudável e como esse conceito se relaciona com seu papel de homem (Ribeiro, 2010). Para Ribeiro (2010) e Moura (2014), o papel do gênero na construção das expectativas e comportamentos de saúde pode ser exemplificado pela maior dificuldade dos homens na busca por assistência à saúde quando estes veem as necessidades de cuidado como uma tarefa feminina.

De toda maneira, seja no trabalho, em casa ou no cuidado com a saúde, a masculinidade é plural, existindo muitas além dessa masculinidade hegemônica. Na medida em que envelhece e vivencia as transformações da vida que lhe trazem a fragilidade 
e a dependência, o ethos masculino se aproxima de outros padrões de masculinidade, considerados subordinados, mas isso permite ao homem idoso reconstruir sua identidade masculina adequando-a a sua realidade (Connel, 2005), como se verá na categoria a seguir.

\section{0 envelhecer $e$ o ser doente}

O envelhecer é encarado de forma positiva quando relacionado às conquistas acumuladas na vida, valorizando as vantagens da experiência e da tranquilidade que o amadurecimento proporciona. Porém, muitas vezes essa visão positiva concorre fortemente com a relação negativa entre o envelhecimento e a fragilização, conforme neste excerto:

O que [a velhice] trouxe de bom foi a tranquilidade, vocêvai ficando uma pessoa mais tranquila, você vai vendo os seus netos, vendo os seus filhos crescerem e conseguindo as coisas, a gente tem, tem as vantagens. Tem as desvantagens também. Você vai ficando mais frágil $\left(\mathrm{H}_{1} 8,65\right.$ anos, casado).

Em geral, os problemas de saúde são atribuídos à velhice, como esclarece este senhor:

Eu falaria que [a saúde] tá mais ou menos que... eu ainda peno de não ter saúde, de tá velho $\left(\mathrm{H}_{12}\right.$, 70 anos, solteiro).

Quanto à avaliação da própria saúde, a maioria dos entrevistados declara a percepção de sua saúde como boa, apesar de eventuais problemas, o que revela certo conformismo em aceitá-los - porque é idoso - e outras questões que participam dessa definição de saúde. Este senhor esclarece:

Relativamente bem, em relação à minha idade tá bem: pressão, pressão controlada, através de remédio. Tomo remédio só pra dormir, mas a minha saúde é boa. Só o que não tá bom é a velhice [risos]. Porque a velhice é doentia. Há um ditado que fala assim: senectus esculopus: a velhice é doentia (H15, 79 anos, casado).
Mesmo entre os entrevistados que declaram possuir alguns problemas de saúde, esses problemas são minimizados, pois o significado atribuído à autoavaliação de saúde relatada como positiva ancora-se na comparação entre o próprio estado de saúde em diferentes momentos da vida ou com o estado de saúde de outras pessoas, em situação considerada pior. Para Fonseca et al. (2010), a discordância entre a autoavaliação de saúde e os dados objetivos da saúde explica-se porque o idoso muitas vezes confunde e sobrepõe envelhecimento, saúde e doença, além de utilizar processos interpretativos que articulam fatores médicos, não médicos e sociais. Isso mostra que o conceito de saúde, assim como outros construtos sociais como o gênero, também tem um caráter relacional, ou seja, é influenciado pelas interações sociais de cada indivíduo (Fonseca et al., 2010).

Um senhor avalia:

Eu tô saudável. Eu não tô sentindo nada [...] eu sou uma pessoa diferente, eu não fico procurando. É igual você pegar um carro, um carro velho. Se você for com ele pro mecânico todo dia, você acha defeito pra ele todo dia [...]. Aí você vai convivendo com um barulhinho (H18, 65 anos, casado).

As concepções de masculinidade e do ideal de envelhecimento saudável compatíveis com uma sociedade produtivista e individualista provocam um esforço do idoso para manter sua autonomia, gerando grande resistência na busca e aceitação de ajuda. Esse comportamento pode, em certa medida, ser benéfico na perspectiva do autocuidado e da responsabilidade por sua própria saúde, mas também pode significar a negação de problemas de saúde ou uma tendência a diminuí-los, tornando-se um risco de acidentes ou agravamento de condições de saúde. Além disso, na cultura local, os entrevistados refletem os discursos biomédico e social (Moraes, 2012), que valorizam as condições físicas que garantem a capacidade para o trabalho e por isso traduzem a velhice em geral como sinônimo de perdas e de doença (Pereira; Firmo; Giacomin, 2014). É possível perceber o entendimento de que os problemas de saúde na velhice são inexoráveis, como se o idoso estivesse 
condenado a sua condição (Giacomin; Santos; Firmo, 2013; Moraes, 2012). Um nonagenário explica porque não faz as atividades de antes:

[...] Mas hoje, esse braço aqui já não aguenta. Sinto uma dor no braço aqui. Já não aguento jogar massa, mexer com massa. Mais, é ficar à toa (H46, 90 anos, viúvo).

Em geral, os problemas de saúde que os entrevistados relatam primeiro relacionam-se àquilo que sentem ou que dói, que afeta o corpo físico e dificulta a realização de atividades cotidianas, em razão de condições agudas como dores, desconforto gastrintestinal, falta de ar, fraquezas. Os problemas de saúde relativos às condições crônicas, apesar de presentes, muitas vezes aparecem com menor ênfase nos relatos dos idosos, exceto quando produzem incapacidade. Ressalte-se que idosos que declararam pior estado de saúde de forma mais intensa, em geral, queixaram-se de problemas incapacitantes. Em um estudo realizado em diferentes países, Low, Molzahn e Schopflocher (2013) também encontraram a forte relação entre as perdas físicas do envelhecimento e a percepção negativa da saúde e da qualidade de vida.

Além das dificuldades e incapacidades trazidas pelos problemas de saúde, a renda é outro caráter que pode colocar o idoso em situação de dependência. Para complementar a renda, alguns dos entrevistados informaram contar com a aposentadoria ou trabalho da esposa, alguns mantêm fontes de renda, e outros declararam precisar contar com ajuda financeira dos filhos, como pode ser visto neste relato:

Então eles [filhos] entraram num consenso lá e resolveram me pagar meio salário todo mês. São sete filhos, então dá. Com isso eu tenho feito a minha renda. Tem a oficina, que não dá nada, mas ajuda (H15, 79 anos, casado).

Com exceção de um, todos os idosos declararam estar aposentados, mas vários se queixaram da insuficiência da renda da aposentadoria e ou da dificuldade para administrar os gastos contando somente com essa renda, principalmente consi- derando os gastos com medicamentos e serviços de saúde particulares. As ressalvas aos serviços de saúde, públicos ou particulares, são muitas e frequentes. Muitos dos idosos informaram não receber todos os medicamentos gratuitamente pelo sistema de saúde, por isso geralmente precisam comprar aqueles medicamentos "mais caros". Um homem explica:

Eu pago. Toda vez que eu vou, tenho que pagar. Pago o remédio, pago a consulta. [...] A gente não sente nada, quando adoece às pressas a gente tem que ir lá consultar, aí eu pego a receita, eles me dá a receita e prevalece quatro meses. Vai acabando, eu vou comprando o remédio até quatro meses (H9, 74 anos, casado).

Quanto às consultas especializadas, para a maioria dos participantes, elas são realizadas fora do município de Bambuí, junto a médicos particulares ou credenciados a planos privados de saúde. Segundo Alcântara e Lopes (2012) o acesso aos produtos e serviços de saúde determina o padrão de consumo de serviços de saúde entre os idosos, ou seja, conforme a oferta de serviços na comunidade onde o indivíduo reside, mas também de acordo com as condições econômicas individuais e familiares, é definido o perfil de consumo de saúde. Dessa forma, a falta de uma maior distribuição geográfica e da oferta de serviços públicos restringe o acesso aos serviços de saúde de indivíduos com piores condições socioeconômicas.

\section{As contradições do cuidado}

Nesta categoria são apresentadas as percepções do grupo sobre os sistemas de cuidado formal e informal.

Um entrevistado enfatiza o cuidado formal e os bons hábitos como forma de alcançar um melhor jeito de se viver:

Ele procurar um médico corretamente, ele fazer os exames igual eu faço... Eu acho que as pessoas depende muito do modo [...] dele agir... Cigarro? Zero. Comida? Boa. Se éuma pessoa mais alegre, 
mais prestativa, uma coisa assim, isso aí eu acho que ajuda mais ainda que as outras coisas. Aíeu acho que a pessoa pode ter mais vida. (Ho6, 62 anos, casado).

Porém, mesmo reconhecendo a importância do cuidado com a pressão arterial, este homem fala:

Eu normalmente, pra te falar a verdade, eu tenho uns cinco anos que eu não consulto [risos]. Ah... não tenho percebido nada assim diferente, por exemplo, uma coisa que eu faço constante é olhar a pressão (H18, 65 anos, casado).

Durante as entrevistas os idosos responderam perguntas sobre os motivos que levam a uma vida saudável e os que conduzem a uma situação de saúde ruim. Em geral, minimizam os problemas de saúde explicando-os a partir da própria culpabilização pela condição atual, o que exime o sistema de saúde da responsabilidade, conforme estes dois excertos:

Eu fiquei nas condições que eu tô aqui agora por ignorância minha mesmo. No tempo que eu era novo, tinha saúde, graças a Deus, o peso que era pra dois eu queria pegar sozinho e muitas das vezes eu peguei. (Ho7, 84 anos, casado).

Músculo do meu coração cresceu. A gente quando é muito novo faz muita força, então ele cresce. $\varepsilon$ a gente não tratava. Não sentia nada, como éque vai tratar? (H25, 74 anos, casado).

Outro homem explica por que não faz exames periódicos:

Pelas lógicas das coisas, não deveria ser assim, você deveria consultar todo ano e tal, fazer exame de próstata todo ano pela minha idade e tudo, mas a minha concepção é diferente. Se aparecer algum problema... imediatamente eu vou procurar o médico, eu vou saber o que que tá acontecendo. Não tá acontecendo nada, eu não vou ficar procurando, procurando doença não. Não tô com doença, não vou procurar doença (H18, 65 anos, casado).
Apesar de uma aparente dicotomia entre a velhice saudável ou doente, a amplitude de conceitos relacionados à saúde e à falta dela foi representada nas falas, ora mais influenciadas pelos conceitos biomédicos, ora seguindo dimensões da cultura. O discurso biomédico, aprendido nos serviços de saúde e em outros canais formais de informação e cuidados em saúde, é repetido principalmente quando se trata de identificar motivos para não estar saudável. Dessa forma, as falas dos idosos estão orientadas no sentido do prejuízo à saúde causado por seus maus hábitos ou pelo simples fato de serem velhos. Todos os idosos relatam o uso dos cuidados formais de saúde, mais intensamente quando percebem o aparecimento ou agravamento de doenças e menos para o controle de condições crônicas, como apresentado por este homem:

Teve um dia à noite aí, veio uma dor danada e todo o jeito que eu mexia na cama tava ruim, aí eu resolvi consultar... Não tô acostumado a ir por isso não. (H40, 71 anos, casado).

Alguns idosos demonstram certa resistência na busca por serviços de saúde, justificada por um comportamento masculino, pela vinculação entre os cuidados formais e a falta de saúde ou mesmo pela visão conformista de que o problema é a idade. Isso demonstra como a relação dos homens idosos com os serviços de saúde é diferente dos homens mais jovens e também diferente das mulheres (Ribeiro, 2010). É possível notar nas entrevistas que a procura pelo cuidado formal em saúde parece ser quase sempre reativa, ou seja, os entrevistados usam os serviços de saúde somente quando apresentam queixas. Essa compreensão corrobora aquela de Moura (2014), segundo a qual, a maior utilização dos serviços de saúde vincula-se àqueles que percebem sua saúde como regular ou ruim.

Na visão dos entrevistados, o sistema formal de cuidado à saúde, não atua na prevenção e promoção da saúde nem na reabilitação. Também nota-se certa desconfiança e até descrença nas técnicas biomédicas, pois, apesar de considerarem a unidade básica de saúde como um serviço de saúde acessível, os entrevistados desconfiam de sua efetividade: 
Quando euvejo que é alguma coisa mais simples eu procuro aqui. Agora, quando eu vejo que émais grave, aí eu vou fora. (Ho6, 62 anos, casado).

Pelo meu problema, os médicos do postinho parece que não é, parece que não é suficiente, não é especializado. (H11, 69 anos, casado)

Embora reconheçam a melhora do sistema público de saúde nos últimos anos, percebe-se que, para os entrevistados, os serviços de saúde do município ainda não suprem toda a demanda de saúde, levando à necessidade de deslocamento para outros municípios em busca de tratamentos, o que contribui para um custo elevado dos cuidados com saúde, além da necessidade de compra de medicamentos, pagamentos de consultas, exames ou planos privados de saúde.

Todos confirmaram receber visitas dos profissionais da ESF, mas não trazem em seus relatos esse fato como uma ação transformadora de suas condições de saúde. Alguns relataram satisfação com as visitas diárias de um profissional, principalmente pela relação de amizade que se estabelece.

Mudou, porque... eu tenho muito amizade com elas... Brincando comigo, aquelas brincadeiras dela: tem que caçar jeito é de viver. Nós ainda quer que você vevi muito ainda. Elas falam: 'Tem que tratar da saúde sim'. $E$.... eu... eu acho bão, eu conversando com ela, assim, igual você, vocês entende a gente, eu entendo vocês. Parece que põe amizade e fica uma coisa boa. [...] eu acho que é uma coisa das melhor que tem que eu acho. Que se a gente tem amizade, a gente tem liberdade de conversar (H12, $7 \mathrm{O}$ anos, solteiro).

Assim, os motivos identificados para se ter uma boa saúde na velhice incluem algo do discurso biomédico, mas o ultrapassam e são lembradas características de bem-estar relacionadas às experiências de vida, à relação com o outro e a valores morais. Também no estudo de Low, Molzahn e Schopflocher (2013) a percepção positiva da saúde esteve relacionada a menores perdas nas relações sociais, manutenção de boa interação social e participação social em grupos organizados.
Embora a promoção da saúde e a prevenção de agravos seja crucial para a ESF, esses homens idosos expressam que o setor profissional do cuidado não cuida da saúde deles, eles o veem como responsável pelo cuidado da doença. Tampouco se observam ações relativas à Política Nacional de Atenção Integral à Saúde do Homem (PNAISH), que traz à tona a vulnerabilidade da saúde dos homens, dada a sua baixa acessibilidade aos serviços de atenção primária, e orienta ações de prevenção de agravos, de promoção da saúde e qualidade de vida e de educação como estratégia de incentivo às mudanças comportamentais. Portanto, é preciso propor ações que valorizem a pessoa mais que suas doenças e incapacidades, o que, segundo Moura (2014), pode significar a garantia de efetividade e provocar mudanças no comportamento dos idosos que passam a confiar mais no serviço, contribuindo para a desconstrução do paradigma cultural da masculinidade vigente.

Para Low, Molzahn e Schopflocher (2013), tornando os ambientes dos serviços de saúde acessíveis físico e psicologicamente aos idosos, cria-se oportunidades para a interação social e permite a realização de objetivos e projetos pessoais. Essa ação promove o sentimento de pertença dos idosos em relação à comunidade. 0 ambiente adequado relativiza a perda psicossocial e física da velhice facilitando a adequação da vida ao período da velhice. Esse mesmo pensamento é oportuno para se pensar a configuração e funcionamento dos serviços, quase sempre feminilizados, que facilitem a inclusão dos homens (Couto et al., 2010).

Muitas vezes a população mais velha quando abordada pelos serviços de saúde, passa por uma “desgenderização" que desconsidera o modo como as características dos gêneros influenciam seus comportamentos (Arber, 2013). Além disso, como a população idosa é majoritariamente feminina, isso favorece a invisibilidade dos homens idosos perante os serviços de saúde, não sendo eles o alvo de trabalhos sobre a perspectiva de gênero nessa população (Ribeiro, 2010).

Assim, é junto à rede social que os idosos (re) constroem sua rotina de atividades, mantendo-se 
socialmente vivos, como pode ser visto nos relatos a seguir:

Tenho muito amigo... Tem muita gente aqui com quem eu posso contar... A família também, nós somo unido, graças a Deus. (Ho3, 74 anos, casado).

Mas eu tenho as amizades que eu tenho, eu tenho prazer disso, sinto prazer das amizades que eu tenho... Faço visita pra alguma pessoa que eu sei que às vezes tá doente [...]. Agora pra passear, às vezes num dia de domingo eu vou na casa duns amigos, eu faço uns papos. Agora, assim, de serviço a gente só vai na casa de uma pessoa que tá doente, perguntar se melhorou, as forças que a gente puder dá ele a gente dá. O que a gente faz é o que a gente recebe. Se a gente não fizer nada pra ninguém também a gente não vai receberné? (H12, $7 \mathrm{O}$ anos, solteiro).

Emerge das falas a importância da rede social formada por familiares ou amigos como suporte à vida e manutenção da saúde de forma próxima, íntima e cotidiana. Quando o homem idoso passa a necessitar de cuidados e ajuda, seja financeira, para moradia, autocuidado ou companhia, a família assume papel essencial, sendo citados esposas, filhos, irmãos, sobrinhos e netos. Essa reflexão aumenta a responsabilidade pela sistematização do cuidado domiciliário no nosso meio, pois é necessário dar suporte à família para que ela cuide do idoso dependente (Giacomin; Uchôa; Lima-Costa, 2005), como estabelecido na Política Nacional de Saúde da Pessoa Idosa (Brasil, 2006).

A vizinhança constitui uma rede de amizade na qual se confia e torna-se motivo para sair de casa, para conversar, para o prazer e também para cuidar e oferecer ajuda. Cornwell (2011) explica em seu estudo realizado com uma amostra representativa da população dos Estados Unidos de 57 a 85 anos que a rede social garante maior suporte social e emocional aos idosos. Porém, segundo o autor, as densas redes sociais mais íntimas, formadas em geral por familiares, podem ser opressoras, realizando um monitoramento rigoroso de seus membros e tornando-se, em algumas situações, um obstáculo para a privacidade e autonomia. Essa característica das redes sociais densas torna importantes as redes menos íntimas, formadas por pessoas conhecidas com as quais se constroem relações mais fracas. Essas redes sociais alternativas, apesar de não substituírem os fortes laços da rede social familiar, aumentam a capacidade dos idosos serem mais independentes e também têm efeito sobre sua autoestima. A aposentadoria e o declínio da saúde para os homens idosos, além de tornarem as tradicionais prioridades masculinas de poder e autonomia mais difíceis de serem sustentadas, também provocam uma queda súbita na rede social "leve" (Cornwell, 2011). Manter redes sociais paralelas representa uma forma informal de poder e independência que pode ser muito favorável à saúde dos homens idosos.

\section{Conclusões}

O ideal produtivista da sociedade ocidental não está apenas no pensamento dos idosos e das pessoas em geral que valorizam o trabalho como atividade econômica, mas se encontra refletido nas instituições de saúde que detectam somente doenças naqueles que não trabalham. Enquanto o foco da atenção aos idosos estiver centrado apenas nas dimensões patológicas, enxergando os velhos de forma estereotipada, como pessoas doentes e dependentes, essa visão não abrangerá a prevenção ou as necessidades psicossociais (Ribeiro, 2010) dos homens velhos. Certamente, essas concepções históricas de masculinidade e produtivismo que trazem prejuízos ao cuidado em saúde dos homens idosos não serão modificadas pela atuação isolada do sistema de saúde ou de um único setor. Mas é possível propor reflexões e mudanças para as próprias ações dos serviços de saúde a partir desses construtos sociais: se a independência é um valor tão caro a esse grupo de pessoas, os serviços de saúde não devem ter o intuito de destituir ainda mais os idosos de sua autonomia, nem buscar tutelá-los.

A ausência do sistema de saúde, principalmente com um caráter preventivo, certamente contribuiu para a atual situação dos idosos. Porém, na visão dos 
homens desse estudo, o cuidado à saúde prevalece no setor informal, em suas redes sociais, enquanto o setor profissional do cuidado fica responsável pelo cuidado da doença.

Para começar a mudar a forma de agir e construir uma atenção à saúde mais abrangente, que reconheça os papéis sociais, crenças e comportamentos como construções socioculturais relacionadas ao gênero (Ribeiro, 2010), é preciso conhecer mais cada homem idoso, suas vulnerabilidades e potenciais, ajudar quando necessário, com o objetivo de construir apoios que preservem ao máximo sua autonomia, que para ele se confunde com a própria saúde. Admitir isso é o primeiro passo para o sistema de saúde modificar essa situação e se responsabilizar de fato com o cuidado à saúde dos velhos, não relegando essa ação somente à esfera da vida privada e a cargo das famílias.

\section{Referências}

ALCÂNTARA, L. R.; LOPES, M. J. M. Estrutura de serviços e acesso a consumos em saúde por idosos em um contexto rural do Sul do Brasil. Redes, Santa Cruz do Sul, v. 17, n. 1, p. 94-114, 2012.

AMADIGI, F. R. et al. Antropologia como ferramenta para compreender as práticas de saúde nos diferentes contextos da vida humana. Revista Mineira de Enfermagem, Belo Horizonte, v. 13, n. 1, p. 139-146, 2009.

ARBER, S. Reflections on "Gender, Health and Ageing": Continuity and change after 2 decades. British Sociological Association. Medical Sociology Online, Durham, v. 7, n. 3, p. 28-37, 2013.

BRASIL. Ministério da Saúde. Política Nacional de Saúde da Pessoa Idosa. Portaria n ${ }^{0} 2.528$ de 19 de outubro de 2006. Brasília, DF, 2006.

BRASIL. Ministério da Saúde. DATASUS. Informações de saúde 2010, 2010. Disponível em: <http://www2.datasus.gov.br/DATASUS/index. php>. Acesso em: 25 mar. 2014.

BURILLE, A. Itinerários terapêuticos de homens em situação de adoecimento crônico: (des) conexões com o cuidado e arranhaduras da masculinidade. 2012. Dissertação (Mestrado em Enfermagem) - Universidade Federal do Rio Grande do Sul, Porto Alegre, 2012.
CONNELL, R. W. Hegemonic masculinity: rethinking the concept. Gender \& Society, Amherst, v. 19, n. 6, p. 829-859, 1 dez. 2005. CORIN, E. et al. Articulation et variations des systèmes de signes, de sens et d'actions. Psychopathologie Africaine, Dakar, v. 24, p. 183204, 1992.

CORNWELL, B. Independence through social networks: bridging potential among older women and men. The journals of gerontology. Series B, Psychological sciences and social sciences, Oxford, v. 66, n. 6, p. 782-94, nov. 2011.

COUTO, M. T. et al. O homem na atenção primária à saúde: discutindo (in)visibilidade a partir da perspectiva de gênero. Interface - Comunicação, Saúde, Educação, Botucatu, v. 14, n. 33, p. 257-270, 2010.

FONSECA, M. G. U. P. et al. Papel da autonomia na autoavaliação da saúde do idoso. Revista de Saúde Pública, São Paulo, v. 44, n. 1, p. 159-165, 2010.

GEERTZ, C. A Interpretação das culturas. Rio de Janeiro: LTC, 1989.

GIACOMIN, K. C.; SANTOS, W. J.; FIRMO, J. O. A. O luto antecipado diante da consciência da finitude: a vida entre os medos de não dar conta, de dar trabalho e de morrer. Ciência \& Saúde Coletiva, Rio de Janeiro, v. 18, n. 9, p. 2487-2496, set. 2013.

GIACOMIN, K. C.; UCHÔA, E.; LIMA-COSTA, M. F. Projeto Bambuí: a experiência do cuidado domiciliário por esposas de idosos dependentes. Cadernos de Saúde Pública, Rio de Janeiro, v. 21, n. 5, p. 1509-1518, 2005.

GUTIERREZ, D. M. D.; MINAYO, M. C. S. Família, redes sociais e saúde: o imbricamento necessário. In: SEMINÁRIO INTERNACIONAL FAZENDO GÊNERO - CORPO, VIOLÊNCIA E PODER, 8., 2008. Anais... Florianópolis: Universidade Federal de Santa Catarina, 2008.

HELMAN, C. G. Cuidado e cura: os setores da assistência à saúde. In: HELMAN, C. Cultura, saúde e doença. 4. ed. Porto Alegre: Artmed, 2003. p. 71-108.

HOUAISS, A.; VILLAR, M. S. Dicionário Houaiss da língua portuguesa. Rio de Janeiro: Objetiva, 2001.

IBGE - INSTITUTO BRASILEIRO DE GEOGRAFIA E ESTATÍSTICA. Dados gerais e informações 
estatísticas da cidade de Bambuí, 2010.

Disponível em: <http://cidades.ibge.gov.br/xtras/ perfil.php?lang $=\&$ codmun $=310510 \&$ search $=$ minas gerais|bambui>. Acesso em: 25 mar. 2014.

KLEINMAN, A. Concepts and a model for the comparison of medical systems as cultural systems. Social science \& medicine, Oxford, v. 12, p. 85-93, 1978.

LOW, G.; MOLZAHN, A. E.; SCHOPFLOCHER, D. Attitudes to aging mediate the relationship between older peoples' subjective health and quality of life in 20 countries. Health and quality of life outcomes, Hamilton, v. 11, n. 1, p. 146, jan. 2013.

MANDÚ, E. N. T. Intersubjetividade na qualificação do cuidado em saúde. Revista LatinoAmericana de Enfermagem, Ribeirão Preto, v. 12, n. 4, p. 665-675, 2004.

MARQUES, A. M. Gênero e saúde: uma relação ainda oculta. In: STREY, M. N.; NOGUEIRA, C.; AZAMBUJA, M. R. (Org.). Gênero e saúde: diálogos iberobrasileiros. Porto Alegre: Edipucrs, 2010. p. 35-58.

MINAYO, M. C. S.; COIMBRA JR., C. E. A. Entre a liberdade e a dependência: reflexões sobre o fenômeno social do envelhecimento. In: MINAYO, M. C. S.; COIMBRA JR., C. E. A. (org.). Antropologia, saúde e envelhecimento. Rio de Janeiro: Fiocruz, 2002. p. 11-24.

MORAES, G. V. O. Influência do Saber Biomédico na Percepção da Relação Saúde/Doença/ Incapacidade em Idosos da Comunidade. 2012. Dissertação (Mestrado em Ciências da Saúde) Centro de Pesquisa René Rachou, Laboratório de Epidemiologia e Antropologia Médica, Belo Horizonte, 2012.

MOURA, E. C. et al. Atenção à saúde dos homens no âmbito da Estratégia Saúde da Família. Ciência \& Saúde Coletiva, Rio de Janeiro, v. 19, n. 2, p. 429438, 2014 .

NARDI, H. C. $\mathrm{O}$ ethos masculino e o adoecimento relacionado ao trabalho. In: DUARTE, L. F. D.; LEAL, O. F. (org.). Doença, sofrimento, perturbação: perspectivas etnográficas. Rio de Janeiro: Fiocruz, 1998. p. 95-104.

O'BRIEN, R.; HUNT, K.; HART, G. "It's caveman stuff, but that is to a certain extent how guys still operate": men's accounts of masculinity and help seeking. Social Science \& Medicine, Oxford, v. 61, p. 503-16, ago. 2005.

PEREIRA, J. K.; FIRMO, J. O. A.; GIACOMIN, K. C. Maneiras de pensar e de agir de idosos frente às questões relativas à funcionalidade/incapacidade. Ciência \& Saúde Coletiva, Rio de Janeiro, v. 19, n.

8, p. 3375-3384, ago. 2014.

RIBEIRO, O. Saúde, masculinidade e envelhecimento: reflexões sociais numa perspectiva de gênero. In: STREY, M. N.; NOGUEIRA, C.; AZAMBUJA, M. R. (Org.). Gênero e saúde: diálogos ibero-brasileiros. Porto Alegre: Edipucrs, 2010. p. 303-324.

SCHRAIBER, L. B.; GOMES, R.; COUTO, M. T. Homens e saúde na pauta da Saúde Coletiva. Ciência \& Saúde Coletiva, Rio de Janeiro, v. 10, n. 1, p. 7-17, 2005.

SCOTT, J. Gender: a useful category of historical analyses. New York: Columbia University Press, 1989. p. 35.

SILVA, S. O.; BUDÓ, M. L. D.; SILVA, M. M. Concepções e práticas de cuidado na visão de homens. Texto e Contexto Enfermagem, Florianópolis, v. 22, n. 2, p. 389-396, 2013.

TURATO, E. R. Métodos qualitativos e quantitativos na área da saúde: definições, diferenças e seus objetos de pesquisa. Revista de Saúde Pública, São Paulo, v. 39, n. 3, p. 507-14, 2005.

UCHÔA, E.; FIRMO, J. O. A.; LIMA-COSTA, M. F. Envelhecimento e saúde: experiência e construção cultural. In: MINAYO, M. C. S.; COIMBRA JR., C. E. A. (Org.). Antropologia, saúde e envelhecimento. Rio de Janeiro: Fiocruz, 2002. p. 25-35.

\section{Contribuição dos autores}

Coelho trabalhou na concepção do projeto; análise e interpretação dos dados e redação do artigo. Giacomin trabalhou na concepção do projeto; análise e interpretação dos dados; e revisão crítica relevante do conteúdo intelectual. Firmo trabalhou na concepção do projeto; coleta, análise e interpretação dos dados; e aprovação final da versão a ser publicada.

Recebido: 17/11/2014

Reapresentado: 21/09/2015

Aprovado: 07/10/2015 